\title{
Mistaking Judgments of the Agreeable and Judgments of Taste
}

Francis Raven

\section{Introduction 1}

$\mathrm{I}$ $\mathrm{n}$ the Critique of the Power of Judgment, Kant develops a rigorous formulation of aesthetic judgments, in which he makes a sharp distinction between judgments of taste and judgments of the agreeable (both of which are, I claim, types of aesthetic judgments) if only to dismiss judgments of the agreeable as worthy objects of study. Kant is primarily concerned with judgments of taste, the main example of which is judging something to be beautiful (whether it be a work of art or a natural object). He asserts that such judgments are subjective, universal, necessary, disinterested, and do not presuppose a purpose. The other type of aesthetic judgment are judgments of the agreeable, "which are the kind of judgment expressed by saying simply that one likes something or finds it pleasing." 2 These are judgments of what, in Kant's words, please "the senses in sensation" as opposed to pleasing our cognition in reflection. ${ }^{3}$

Let me be clear from the outset by saying that judgments of the agreeable are not Kant's primary concern. Using the terminology of the Critique of Pure Reason, judgments of the agreeable properly belong to sensibility, while judgments of taste (and thus, of the beautiful) belong to the understanding and finally judgments of the good belong to reason. Kant is first and foremost interested in the understanding and reason and thus in judgments of taste and of the good. That said, to fully understand judgments of taste, judgments of the agreeable cannot be neglected. As Nick Zangwill writes of judgments of the agreeable (which he calls judgments of "niceness and nastiness"), "by and large, the interpretation of what Kant says about beautiful things hinges on what he says about the agreeable, rather than the

1 Helpful comments were made to the conference version of this paper at the American Society for Aesthetics Eastern Division Meeting (April 2007). Thanks both to Moris Stern's formal comments and to the other participants for their help. In addition, Noël Carroll, Carol Gould, Paul Guyer, and Kristin Gjesdal instrumentally aided in the writing of this paper. Thanks for all their help. Philosophy (2005).

2 H. Ginsborg, "Kant's Aesthetics and Teleology," in The Stanford Encyclopedia of

${ }^{3}$ I. Kant, Critique of the Power of Judgment (Cambridge: Cambridge University Press, 2000). 


\section{F. RAVEN 113}

other way around. So if we are interested in what Kant says about the beautiful, it is important to get him right on the agreeable." 4 In this paper I follow on this premise of Zangwill's and take a closer look at judgments of the agreeable and how they compare with judgments of taste. This examination leads me to argue that the rigid distinction between judgments of the agreeable and judgments of the beautiful is not tenable and that this makes it difficult to delimit the sphere of the beautiful. Thus, my contribution will be to show how the lack of a rigid distinction between these types of judgments threatens to undermine a Kantian aesthetics since, if this distinction cannot be made, the realm of the beautiful cannot be delimited.

In the next section of the paper I discuss how Kant distinguishes judgments of taste from judgments of the agreeable, highlighting the role a particular type of interest plays in this distinction. I then explore the possibility that this type of interest does not perfectly distinguish these two categories of aesthetic judgment. This suggests that a rigid theoretical distinction between these types of judgment is not possible. In the third section of the paper I discuss how we often mistake judgments of the agreeable for judgments of taste (and vice versa) such that there is not a practical distinction between the two types of aesthetic judgments. That is, in the paper I will show that there are both theoretical and practical impediments to systematically distinguishing judgments of the taste and judgments of the agreeable. In section $4 \mathrm{I}$ then offer a possible solution to this problem, namely, categorization. I conclude in section 5 by noting that despite attempts at overcoming the mistakes we make through categorization, these mistakes - and Kant's rigid distinction between judgments of the agreeable and judgments of taste-continue to pose a problem for Kantian aesthetics.

\section{Types of Aesthetic Judgment: the Agreeable and the Beautiful}

\subsection{Comparison Cases}

Kant introduces judgments of the agreeable in the Critique of the Power of Judgment in the context of differentiating judgments of the beautiful from both judgments of the agreeable and judgments of the good. That is, judgments of the agreeable and judgments of the good are provided as comparison cases to judgments of the beautiful. To distinguish a judgment of taste, a person is supposed to be able to reflect upon her feeling of pleasure, while reviewing the characteristics of judgments of the beautiful (provided by Kant in the four movements of the "Analytic of the Beautiful"). By asking herself questions about the nature of her pleasure, she can eliminate judgments of the agreeable and come to see that her judgment was a judgment of the beautiful. However, in order for such an exercise in elimination to work, Kant

${ }^{4}$ N. Zangwill, "Kant on Pleasure in the Agreeable," in Journal of Aesthetics and Art Criticism, 53:2 (1995), 167-176. 


\section{MAKING JUDGMENTS}

must have thought that judgments of the agreeable and of the good were similar enough to judgments of taste to provide meaningful comparison cases, and yet completely distinct from them.

The agreeable is similar to the beautiful in that it is aesthetic, by which Kant means, in part, that its "determining ground cannot be other than subjective. Any relation of representations, however, even that of sensations can be objective. . . but not the relation to the feeling of pleasure and displeasure, by means of which nothing at all in the object is designated . ..."5 Aesthetic judgments involve the senses and are essentially judgments for me, involving pleasure or displeasure. We must be careful, however, not to confuse judgments of impure beauty with judgments of the agreeable. Judgments of impure beauty involve a concept, but are reflective judgments that involve more than the pleasure of our "senses in sensation." The good, on the other hand, which I will not treat in this paper, is "what is esteemed, approved, i.e. that on which he sets an objective value." Both judgments of the good and judgments of the agreeable are "combined with interest" (\$3-4) whereas judgments of beauty are not combined with interest. I will return to the notion of interest in more detail below.

In the second moment of the "Analytic of the Beautiful" Kant discusses the universal validity of judgments of the beautiful, something that sets them apart from judgments of the agreeable. For Kant, what makes judgments of taste peculiar is that they are both subjective and universally valid. Being subjective means that, like judgments of the agreeable, judgments of taste are essentially judgments for me. Being universally valid, when we speak of beauty we do not merely speak of our own opinions or feelings but demand that others see this beauty as well. As Kant famously wrote, when a man "pronounces that something is beautiful, then he expects the very same satisfaction of others: he judges not merely for himself, but for everyone, and speaks of beauty as if it were a property of things." 7 It is the combination of these two properties, ${ }^{8}$ subjectivity and universality, that makes judgments of taste unique. ${ }^{9}$

\footnotetext{
${ }^{5}$ Kant, op cit.

${ }^{6}$ Ibid.

${ }^{7}$ Ibid.

${ }^{8}$ In addition, the judgment of taste is not based on a concept and this distinguishes it
} from judgments of the good. As Kant writes, "[O]ne must be fully convinced that through the judgment of taste (on the beautiful) one ascribes the satisfaction in an object to everyone, yet without grounding it on a concept (for then I would be the good), and that this claim to universal validity belongs so essentially to a judgment by which we declare something to be beautiful that without thinking this it would never occur to anyone to use this expression, rather everything that pleases without a concept would be counted as agreeable, regarding which everyone can be of his own mind, and no one expects assent to his judgment of taste of anyone else, although this is always the case in judgments of taste about beauty.” Ibid., \$8.

9 Hannah Ginsborg argues that this combination of subjectivity and universality involved in judgments of taste implicates the idea of necessity (the fourth moment of the Analytic of the Beautiful, which I will not discuss in this paper) since "in taking my judgment of beauty to be universally valid, I take it, not that everyone who perceives the object will share my 
Despite the subjectivity of judgments of taste, Kant argues that the universal validity of subjective judgments of taste is guaranteed by common sense. $\mathrm{He}$ writes that common sense is the subjective principle "which determines what pleases or displeases, by means of feeling only and not through concepts, but yet with universal validity." 10 Our aesthetic judgments are subjective, yet because others share common sense we demand that others share our judgments of taste. And indeed, this is how Kant's famous deduction proceeds. Our subjective aesthetic judgments are universally communicable because we possess the sensus communis. As Douglas Burnham writes in his Introduction to Kant's Critique of Judgment, "Commonness is built right in to the very notion of aesthetic judgment." 11 However, it is "not in the everyday sense of a minimal level of understanding of things. It is, literally, the only dimension of sensing (rather than understanding) that is shared by everyone."12 As Kant writes, "by the sensus communis one ... understands the idea of a public sense, that is, a faculty of estimation which in its reflection takes account (a priori) of the mode of representation of everyone else, in order as it were, to weigh its judgment against the collective reason of mankind and thereby escape the illusion which arises from subjective private conditions that may easily be taken to be objective, [and] that would have a disadvantageous influence on the judgment." 13 To demand that another shares our judgments of taste requires that these judgments be communicable. The sensus communis is what enables individuals to communicate their judgments of taste. We can argue about them, defend them, convince others of their validity, etc. in a way that we cannot concerning judgments of the agreeable.

Judgments of the agreeable, on the other hand, are also subjective, but not universally valid. If I say "I like the ocean because it is blue," and blue is my favorite color, I am not undergoing an experience of the beautiful, but merely feeling something agreeable. In judgments of the agreeable we find the object in question pleasurable; whereas judgments of taste are based instead on the subjective feeling of pleasure we have when our cognitive faculties of imagination and understanding have been brought into harmony.

Unlike judgments of taste, judgments of the agreeable are not universally valid, but are instead only generally valid. That is, they apply only to "most but not to all men." 14 However, this does not mean that every person might not, as a matter of fact, share the same judgments concerning the agreeable. As Kant wrote, "Nevertheless, one finds with regard to the agreeable that unanimity in their judging of it may be encountered among people, in view of which taste is denied of some of them but conceded to

pleasure in it and (relatedly) agree with my judgment, but that everyone ought to do so." Ginsborg, op cit.

${ }^{10}$ Kant, op cit., $\$ 20$

11 D. Burnham, An Introduction to Kant's Critique of Judgment (Edinburgh: Edinburgh University Press, 2000).

12 T. Gracyk, Hume and Kant: Summary and Comparison (2004).

${ }^{13}$ Kant, op cit.

${ }^{14}$ N. Zangwill, "Aesthetic Judgment," in The Stanford Encyclopedia of Philosophy,_(2003). 


\section{MAKING JUDGMENTS}

other. ${ }^{15 "}$ The primary consequence is that individuals do not regularly expect others to make the same judgments of the agreeable as they do. Thus, judgments of the agreeable say more about ourselves than they do about the aesthetic objects we are ostensibly judging. Zangwill continues summing up the difference between judgments of taste and judgments of the agreeable by writing, "If I get pleasure from drinking Canary-wine, and you don't, neither of us will think of the other as being mistaken. But if you don't get pleasure from Shakespeare's Sonnets, I will think of you as being in error-not just your judgment, but your liking. I think that I am right to have my response, and that your response is defective. 1 .

\subsection{Interest}

The primary axis on which I am going to compare judgments of the agreeable and judgments of taste is not universal validity but interest. In $\$ 2$ Kant defines an interest by writing that it is "the satisfaction we combine with representation of the existence of an object," 17 and in $\$ 3$ he writes that the pleasure derived "in the agreeable is combined with interest."18 Nick Zangwill's article "Kant on Pleasure in the Agreeable," addresses the question of interested and disinterested pleasure. He writes, by way of definition that, if 'pleasure is an 'interest,' in Kant's sense, it means that it bears an intimate relation to a desire (that is, a concern with real existence). An 'interest' is a pleasure that has some kind of necessary connection with a desire. A pleasure is 'disinterested' if it has no such necessary connection with desire . ..."19 As Kant wrote, "One can say that among all these three kinds of satisfaction only that of taste for the beautiful is a disinterested and free satisfaction; for no interest, neither that of the senses nor that of reason, extorts approval." 20

There are two basic types of interest which are aesthetically important: the first is when the subject has an interest in a piece of fine art that goes beyond its aesthetic properties. This type of interest includes situations in which a person likes a painting because it is, for example, (a) historically interesting, (b) ethically appealing, or (c) in fashion. ${ }^{21}$ In this case, the viewer could not have an aesthetic interest in the work at all (and thus, could not make even a judgment of the agreeable about the work). This type of interest divides aesthetic judgment from non-aesthetic judgment (and thus, both judgments of taste and judgments of the agreeable can be said to be disinterested in this way). In these cases of interestedness there would be no free play of the faculties of understanding and imagination since the work in question would be

\footnotetext{
15 Kant, op cit.

16 Zangwill, "Aesthetic Judgment."

${ }^{17}$ Kant, op cit.

18 Ibid.

19 Zangwill, "Kant on Pleasure in the Agreeable."

${ }^{20}$ Kant, op cit.

${ }^{21}$ It should be noted that this is not an exhaustive list, but merely a laundry list of
} reasons. 
placed under a concept before the understanding and the imagination are able to come into harmony in the judgment of the beautiful.

There is a second type of interest, however, that separates judgments of the agreeable from judgments of taste. This type of interest exists when the subject desires the work in question because of aesthetic properties that only affect his senses. This is how we feel in the face of an agreeable work. Another way of putting this (as Kant does in \$2) would be to say that this type of interest refers to the fact that the object we are judging actually exists. If we have an interest in that object actually existing then we are merely making a judgment of the agreeable. If, on the other hand, it does not matter whether the object at hand exists or not then it is possible that the work could "satisfy our cognition" 22 and we will have made a legitimate judgment of taste. Kant's claim is not that we shouldn't want to own a Picasso or a postcard of it-for we do, in fact, obtain pleasure from it-but instead that our judgment of taste concerning the Picasso is independent of and logically prior to our enjoyment of owning the Picasso. As Kant writes, "One only wants to know whether the mere representation of the object is accompanied with satisfaction in me, however indifferent I might be with regard to the existence of the object of this representation." 23 Thus, the question is not: how do we know whether it matters if a work exists or not? After all, all actual works which we judge do exist. The question is rather: how does the work's existence affect our aesthetic judgment of the work?

If a work merely satisfies a person's senses then she necessarily has an interest in the work's existence. Since the subject desires the agreeable, viewing it can be said to be interested in this second sense. The agreeable must exist; otherwise it would not be pleasurable and could not be desired. This second type of interest is perhaps troubling for a Kantian aesthetics as it does not neatly divide judgments of the agreeable from judgments of taste. There are two potential problems for Kant, here. First, it could be the case that some judgments of the agreeable are disinterested. Second, some judgments of taste might be interested. I will discuss each of these possibilities in turn.

\section{2a What if Some Judgments of the Agreeable Are Disinterested? The Case of Sated Pleasures}

In his article "Kant on Pleasure in the Agreeable," Nick Zangwill outlines the possibility that some judgments of the agreeable are disinterested, which I will discuss here. For the purposes of his paper, Zangwill divides interested pleasures into the primitively and productively interested pleasures, the latter of which he believes Kant equates with judgments of the agreeable. He defines 'primitively interested' pleasures as "those pleasures which are generated by a desire" and 'productively interested' pleasures "those pleasures

\footnotetext{
22 Burnham, op cit.

${ }^{23}$ Kant, op cit.
} 


\section{MAKING JUDGMENTS}

which generate desire." 24 He explains interested pleasures with a story of Canary wine:

I conjecture that the story would be as follows in the case of the pleasure of Canary wine. To begin with, I taste the wine. The wine has a certain flavor-a secondary quality like the greenness of a meadow. I get pleasure from tasting the flavor. As a result, I judge that it is nice (agreeable). So far so good, except that desire has not as yet made an appearance. Desire appears as follows: I represent another glass of wine as having a similar flavor. I conclude that it too would be nice. I am then led to desire another glass of wine as a potential source of more pleasure. The pleasure in sensation has an inevitable tendency to provoke desire, given the thought of similar sensations. I shall call this the 'representational' interpretation of Kant's view of the production of desire by pleasure in the agreeable. ${ }^{25}$

Zangwill's representational theory of interest explains interest with reference to the desire for similar objects - he desires another wine with a similar taste. This is an interested pleasure.

Zangwill's representational view can be opposed to a more causal view of interest, which would entail a much more direct relationship between the object of desire and the desire. The story of the causal theory would be much simpler: the chocolate bar sitting on the table causes us to desire it simply because we know how it tastes when we put it in our mouths. "An agreeable object pleases by means of a purely physiological effect on the senses, and no particular conception of the object is required for its production of this pleasure."26 This causal story does not explain why we desire other chocolate bars, as Zangwill's representational theory does, but we could expand the causal explanation to do so. As Paul Guyer writes, "if the experience of pleasure in an agreeable object does depend on the senses alone, and is due to a causal relation between properties of an object and one's own physiology, then one may come to believe in a lawlike connection between objects of that sort and the experience of pleasure-at least for oneself." 27 What Zangwill's theory does, however, is to specify the mechanism of this "lawlike connection."

In his paper, Zangwill moves on to show how primitively interested non-intentional pleasures are normally interested. He interprets Kant as saying that pleasures in the agreeable are productively interested. This is where the question arises as to whether some pleasures of the agreeable might not, in

\footnotetext{
${ }^{24}$ Zangwill, "Kant on Pleasure in the Agreeable."

25 Ibid.

${ }^{26}$ P. Guyer, Kant and the Claims of Taste (Cambridge, Cambridge University Press, 1997).

${ }^{27}$ Ibid.
} 
fact, be interested. Zangwill asks, "How plausible is Kant's claim that all pleasures in the agreeable are productively interested because they provoke desire when something else is represented as similar in the pleasure-inducing respect?"' 28 He thinks that in most cases it is plausible, but his counterexample of sated pleasures shows that it is possible for an agreeable pleasure not to be interested (at least for a moment):

Take chocolate. Chocolate, as is well known, is 'moreish.' One might fancy just one piece. But we soon find ourselves beset by a desire to go for a second. And then a third. But this does not go on forever. At some point, we have had enough.. Now, what about the last piece that we enjoy just before we have had enough? Call this last pleasure 'sated pleasure.' Are 'sated' pleasures interested? Surely a sated pleasure does not produce a desire for more in the way that Kant says. So sated pleasures seem to be counterexamples to Kant's thesis about the agreeable. And anyway, Kant's view seems problematic in that if he says that pleasure in the agreeable always produces desire, then how could someone fully supplied ever stop eating chocolates? 29

Using the example of sated preferences, Zangwill has shown that some agreeable pleasures are not productively interested (at least at the moment of being sated). It should be noted here, first, that this argument only applies to productive interest in non-intentional agreeable pleasure, and second, that there are strategies that one might employ for Kant to maintain that all judgments of the agreeable are interested. Zangwill outlines such a possibility, "Kant might argue that having had the pleasure, one would be motivated to regain a similar pleasure if one were to become aware that one is once again in a similar unsated situation. Despite one's present apathy, one is disposed to steer oneself in the direction of more chocolate on suitable further occasions." 30

This appears to be a sound response to Zangwill's case of sated pleasures initially, but a counter example will show that it is at least possible that such an argument does not always hold. What if one overeats and does not believe they will ever be able to get back to their unsated self? The general thesis of psychologist Daniel Gilbert's Stumbling on Happiness, is that people are not very good at making predictions about their future selves. He presents the overeating example in his book: "I can recall a Thanksgiving (well, actually most Thanksgivings) when I ate so much that I realized only as I swallowed my last bite of pumpkin pie that my breathing had become shallow and labored

\footnotetext{
${ }^{28}$ Zangwill, "Kant on Pleasure in the Agreeable."

${ }^{29}$ Ibid.

${ }^{30}$ Ibid.
} 


\section{MAKING JUDGMENTS}

because my lungs no longer had room to expand. I staggered to the living room, fell flat on the couch, and, as I descended mercifully into a tryptophan coma, was heard to utter these words 'I'll never eat again'." ${ }_{11}$ It seems that in this case at the moment Gilbert is lying on the couch, he would not be "disposed to steer" himself in the direction of more pumpkin pie "on suitable further occasions." Gilbert's notes that empirical research supports this notion: "[r]esearch in laboratories and supermarkets has demonstrated that when people who have recently eaten try to decide what they will want to eat next week, they reliably underestimate the extent of their future appetites." 32 To the extent Gilbert is correct that people are not able to forecast a change in their state-such as realizing that he will indeed be hungry again in the future-Kant's strategy of responding to sated pleasures that Zangwill proposes would fail. Thus, it certainly seems that in certain circumstances judgments of the agreeable will be disinterested, such as when the stuffed Gilbert on the couch notes that turkey tastes good.

\section{2b What if Some Judgments of the Beautiful Are Interested? The Case of Pride in Ownership}

In the "Definition of the beautiful derived from the first moment" Kant writes that "Taste is the faculty for judging an object or a kind of representation through a satisfaction or dissatisfaction without any interest." 33 As Henry Allison notes, according to Kant's claim that judgments of the beautiful must be disinterested they "must be independent of any concern for the existence of the object of that liking." 34 That is, they must be disinterested in the second of the ways outlined in Section 2.2. In this section of the paper I will show that sometimes judgments of the beautiful are actually interested in this way.

It is possible to state that by definition, judgments of the beautiful are never interested and that if they are, they are not pure judgments of taste. In $\$ 2$ Kant seems to do this when he writes, "Everyone must concede that a judgment on beauty, in which the least interest mingles, is very partial and no pure judgment of taste. One must not be in the least prejudiced in favor of the existence of the thing, but be quite indifferent in this respect, in order to play the judge in matters of taste." 35 However, in this section of the paper I will assume that it is, in theory, possible for a judgment of the beautiful to be interested especially in the case of judgments of adherent (or impure) beauty (which I will more fully address when I outline a possible method for avoiding mistakes between judgments of the agreeable and judgments of the beautiful). For if it is not, in theory, possible for a judgment of taste to be interested

${ }^{31}$ D. Gilbert, Stumbling on Happiness (New York: Knopf, 2006).

32 Ibid.

${ }^{33}$ Kant, op cit.

${ }^{34}$ H. E. Allison, Kant's Theory of Taste, A Reading of the Critique of Aesthetic Judgment (Cambridge: Cambridge University Press, 2001).

${ }^{35} \mathrm{Kant}$, op cit. 
(partially or otherwise) then it might turn out that there was never, and could not possibly be, a pure judgment of taste. That is, I don't think that it is false by definition that judgments of taste can never be interested; it is something that must be shown. For, in this paper, I am also assuming the judgments of taste are judgments that people make on a fairly regular basis and as such, can be investigated.

Other scholars have also argued that it must be shown that judgments of taste can never be interested. Henry Allison wrote that one of the questions that need to be answered with regard to the disinterested pleasure of the beautiful, is whether "a disinterested liking or pleasure is possible at all, particularly given Kant's subsequent characterization of pleasure as the 'consciousness of a representation's causality directed at the subject's state so as to keep him in that state.' Since any pleasure thus involves an endeavor to maintain itself, it might seem that it must likewise involve an interest in the continued existence of whatever is responsible for producing this state in the first place." 36 Or, as Paul Guyer writes, "In \$3, Kant differentiates pleasure in a beautiful object from that in an agreeable one by claiming that the latter produces an interest in further experiences of the same sort, and implying that the former does not. However, it appears to be a defining characteristic of any kind of pleasure that it produce an interest in its own continuation, and this makes the difference between the beautiful and the agreeable obscure indeed." ${ }^{37}$ That is, in Zangwill's language discussed above, Guyer is saying that it looks like some judgments of the beautiful are productively interested.

One thing is certainly true: we do often care deeply about the continued existence of the objects of our judgments of the beautiful. This is easily seen in the fact that we, as a society or as individuals, do, in fact, spend a lot of time, energy, and money in order to preserve works which elicit a judgment of taste. The key, however, is that for a judgment to be a judgment of taste, the aesthetic pleasure that the object (or the representation of it) brings is supposed to trump all other considerations, including whether it continues to exist or not. As Guyer writes, "Our readiness to dismiss ... other answers [for why something might be beautiful] to a request for aesthetic judgment, in other words, is supposed to show that we all acknowledge the difference between contemplation of a representation and approval of actual existence, and that the identity of aesthetic response with the first of these may serve as a starting point for an aesthetic theory." 38 That is, to proclaim that a judgment has been a judgment of taste as opposed to a judgment of the agreeable we go through a process of elimination where we ask ourselves if we have an interest (of several kinds, whether it is morally superior, whether we are attached to it for sentimental reasons, whether we care about its continued existence, etc.) and if we find that we do not have such an interest then we can proclaim that we have had a judgment of the beautiful.

\footnotetext{
36 Allison, op cit.

${ }^{37}$ Guyer, Kant and the Claims of Taste.

38 Ibid.
} 


\section{MAKING JUDGMENTS}

However, there are cases in which it is reasonable to believe that a judgment of taste is being undertaken but that it might be, at least partially, interested. Paul Guyer notes two such circumstances. First, if "only one object can occasion a particular beautiful representation - if only the Mona Lisa originally painted by Leonardo can give us an adequate representation of the Mona Lisa-then it is completely natural that the pleasure we derive from the representation of that object should lead us to desire its continued existence."39 It is reasonable to assume that in all such cases of uniqueness, the pleasure we feel will be intimately related to the continued existence of the object. And yet, we still would want to call the judgment about such an object a judgment of taste. On the other side of the spectrum, "a genuine delight in the beautiful need [not] be able to survive any amount of repetition or imitation . . . the effect of repetition on aesthetic response may be the same as that of rulegovernedness, namely destruction of the at least apparent contingency of synthesis on which pleasure in the beautiful rests." 40 Even if the a person's judgment of the Mona Lisa changes in the face of the onslaught of Mona Lisa postcards, we can still call this person's original judgment a judgment of taste because the existence of the original Mona Lisa has been altered. Thus, there are at least two cases in which a judgment of taste can be, at least partially, interested in the continued existence of its object.

As I have shown in the preceding sections, it is possible that in some cases judgments of the agreeable might be (at least productively) disinterested and judgments of taste might be interested. This signals the possibility, which I will discuss below, that individuals may sometimes mistake judgments of the agreeable for judgments of the beautiful (and vice versa). This practical confusion, coupled with the theoretical inability to distinguish judgments of taste for judgments of the agreeable, both go to show that the judgments of the agreeable and judgments of taste are not analytically distinct. However, I am not saying that there is a causal connection (in either direction) between (a) the fact that some judgments of the agreeable might be distinterested (and that some judgments of the beautiful might be interested) and (b) the fact that we sometimes mistake judgments of the agreeable for judgments of taste (and vice versa). Both of these are examples of ways in which judgments of the agreeable and judgments of taste might not be conceptually distinct, a possibility that undermines a Kantian aesthetics.

\section{Mistakes We Make}

Thus far, I have outlined the key differences between judgments of taste and judgments of the agreeable and have shown some theoretical ways in which the rigid distinction between them is not tenable. Now I want to move on to show some practical ways in which this distinction may not be as rigid as Kant supposes. That is, we do, in fact, mistake judgments of the beautiful for

$$
\begin{aligned}
& { }^{39} \text { Ibid. } \\
& { }^{40} \text { Ibid. }
\end{aligned}
$$


judgments of the agreeable and vice versa. When I say that we make mistakes I am saying that if we assume that a rigid categorization between the agreeable and the beautiful exists we will often make mistakes between these categories since differentiation is not always clear. Of course, Kant foresaw the possibility that we would make errors regarding judgments of taste. As he wrote in the footnote to $\$ 38$, "If an error is made ... that concerns only the incorrect application to a particular case of the authority that a law gives us, by which authority in general is not suspended." 41 However, if we routinely mistake one "category" for another (as I think we mistake judgments of the agreeable and judgments of the beautiful) it is an indication that these categories are not analytically distinct. I thus discuss each type of mistake in turn. Each of these mistakes has a proximal consequence and then a larger consequence which is more important for the Kantian aesthetic project and which I will discuss in the conclusion.

\section{Two Types of Mistake}

\subsection{Mistaking Judgments of Taste for Judgments of the Agreeable}

Sometimes we mistake judgments of taste for judgments of the agreeable (examples of which I will turn to in a moment). There are many reasons for making such mistakes. These include, but are not limited to (a) the psychological (when we are not sure of our own position); (b) the philosophical (when we cannot philosophically justify the judgment); (c) the sociological (when the aesthetic community to which we belong does not conceive of a particular judgment of taste to be universally valid or does not hold the distinction between judgments of taste and of the agreeable); or (d) the educational (when our educational level is not high enough for us to conceive of universally valid statements). ${ }^{42}$

An example of mistaking a judgment of taste for a judgment of the agreeable would be the following: You visit the Museum of Modern Art with a close friend. You're in the large room with Monet's $W$ aterlilies. You say to her "That is such a beautiful painting. The rhythm of the shapes, the composition of the forms, the quality of the brushstrokes are so masterful. And the painting as a whole captures us in the moment of perception; that really is what it's like to see the light on waterlilies. They truly are beautiful, don't you think?"

Your friend brashly responds, "This is kind of embarrassing, but I actually don't find them beautiful. And not only that, but I don't think they are beautiful. They're fuzzy and sentimental and generally overrated. The fact that you find them beautiful is great and all, but it's just an example of your own

\footnotetext{
${ }^{41}$ Kant, op cit.

${ }^{42}$ It should be noted that this is not an exhaustive list, but merely a laundry list of
} reasons. 


\section{MAKING JUDGMENTS}

personal taste. Someone else could say that the $W$ aterlilies really aren't beautiful and they would be correct as well because that would be their own subjective taste." Here, your friend has made a mistake in her judgment. She somehow has not responded to the work with the appropriate reaction of pleasurable, subjective reflection. It should be noted that judgments concerning fine art are judgments of impure or adherent beauty, but this does not mean that they are not legitimate judgments of the beautiful. The question is not whether the work is beautiful or not but whether the judgment has been a judgment of the beautiful. Even though no proof for the judgment of the beautiful can be offered, you have made such a demand of your friend. When her faculties were not brought into harmony and she failed to have such a judgment, she made a mistake thinking a judgment of the beautiful was a judgment of the agreeable. Perhaps your friend's judgment was connected with interest (perhaps she had just seen the painting etched on too many coffee cups) and thus could not have been a judgment of taste. But in the context observed here, when your friend failed to have a judgment of taste she made a mistake in judgment. That is, if we are observing strict boundaries between judgments of the agreeable and judgments of taste, then your friend has made a mistake.

The proximal consequence of such a mistake would be the belief that even in judgments of the beautiful "each to their own taste" would apply or believing that it is true that "everyone has different tastes," or as one Russian proverb puts it, "in taste and color there are no friends." In terms of aesthetic judgments, it is the belief that all aesthetic judgments of the beautiful are equally valid; that judgments of taste are not universally, but only personally, valid.

\subsection{Mistaking Judgments of Taste for Judgments of the Agreeable}

The opposite mistake also occurs; that is, we often mistake judgments of the agreeable for judgments of beauty. An example of this would be would be: After eating a lavish seven-course dinner that a famous chef has cooked for you personally, you compliment him by saying, "That meal made me feel so good. It was a truly beautiful meal in every sense of the word. I say this in all honesty: if anyone did not find your seared foie gras perfectly sensuous, an example of a food that is beautiful, she would be wrong, dead wrong. Everyone should find your dishes among the beautiful." 43

43 There are other examples of this mistake. For instance, my wife loves real maple syrup. She hates fake maple syrup. She thinks that anyone who likes fake maple syrup better than real maple syrup (and there are those who have this preference) are wrong, dead wrong. She is incredulous that anyone would have this preference because she thinks that her preference for real maple syrup, her belief that it is more "beautiful" than fake maple syrup is universally valid. (Admittedly, she would not use the word beautiful in this context, but I think she is making, or thinks she is making, a judgment of taste).

Whereas an example of mistaking a nonaesthetic judgment for a judgment of taste would be the following: After seeing the rather trite movie, "The Prince and Me," your viewing companion says, "The Prince and Me was the most beautiful movie I've ever seen. It really 
Again your friend has made a mistake in her judgment. In this example, she has a mistaken judgment of the beautiful when the object in question (food) is not capable of causing a free play of the understanding and the imagination. The question here, again, is not whether the dinner is great or not, but whether the judgment has been a judgment of the beautiful or the agreeable. In the framework of a Kantian aesthetics, an aesthetic object such as a dinner can only be a judgment of the agreeable. This is true since food can only, says the Kantian, "please the senses in sensation" and cannot help but produce an interest in that kind of food's continued existence. That is, food is not a species of impure beauty, but is instead a species of the agreeable since it does not cause the free play of the faculties. Since no proof of a judgment of taste can be offered, it might seem that mistaking a judgment of the agreeable for a judgment of the beautiful would not be a mistake but a case in one person's faculties were in pleasurable free play (and so issued a judgment of the beautiful) and another person's senses were merely pleased in the sensing. In the case of the lavish dinner, however, this is a mistake because a lavish dinner is not the type of object that could cause the free play of the faculties (at least, if we are taking the agreeable and the beautiful as rigidly distinguishable). Perhaps what this means is that only when we are sated (at least with something that would normally produce a judgment of the agreeable) can such an object produce a judgment of the beautiful. But in the context observed here, when your friend failed to have a judgment of the agreeable, she made a mistake in judgment. That is, if we are observing strict boundaries between judgments of the agreeable and judgments of taste then your friend has made a mistake.

One hypothesis for why this error occurs is that people have a tendency to believe that all of their aesthetic judgments have universal validity. Due to this natural inclination, we are often unable to differentiate our own judgments of taste and of the agreeable. This is a point that Hume stressed when he wrote, "It is natural for us to seek a Standard of Taste; a rule by which the various sentiments of men may be reconciled . . . at least a decision afforded by confirming one sentiment, and condemning another." 44 Paul Guyer remarks that this naturalness "might be taken to express [Hume's] view that there is no justification or even explanation of our pursuit of agreement in subjective preferences, that this pursuit is just one of those points at which the explanations that can be offered by a Newtonian physics must come to an end." 45 Is making the mistakes discussed above simply the cost of making judgments about aesthetic objects? Perhaps the nature of our senses makes

shows how far women have come and how the metaphysics of feminism has entered into our discourse. If anybody doesn't just think this is the most beautiful movie they're a sexist and have no taste in movies." Your friend was interested in the movie for its political significance and thus could not be making an aesthetic judgment.

${ }^{44}$ D. Hume, "Of the Standard of Taste," in Essays: Moral, Political, and Literary, trans. by E. F. Miller. Indianapolis: Liberty Fund, 1985).

45 P. Guyer, Values of Beanty: Historical Essays in Aesthetics (Cambridge: Cambridge University Press, 2005). 


\section{MAKING JUDGMENTS}

these mistakes inevitable. When we view art, we first sense the aesthetic object and only after does our cognition grasp it. Perhaps an individual cannot properly distinguish between activities of the mind and activities of the senses. If so, there is no practical or analytically rigorous way to differentiate between judgments of the agreeable and judgments of taste.

\section{A Concluding Strategy: Categorization}

Theoretically we have seen that it is not possible to fully separate judgments of taste from judgments of the agreeable according to interest. It is also the case that humans have a tendency to mistake the two categories. If the nature of our senses makes it impossible to always distinguish judgments of taste from those of the agreeable, it seems that such a distinction between these two categories may be untenable. There is, however, one possible way in which such mistakes might be able to be overcome - categorization. I will discuss this possibility here.

Throughout this essay I have not been distinguishing between types of beauty so that my argument would be clearer. However, in order to understand the strategy I propose for avoiding making the mistakes I have outlined above it is necessary to make this distinction now. Kant distinguished between two types of beauty: free beauty (pulchritudo vaga) and adherent beauty (pulchritude adhaerens). "The first presupposes no concept of what the object ought to be; the second does presuppose a concept and the perfection of the object in accordance with it. The first are called (self-subsisting) beauties of this or that thing; the later, as adhering to a concept (conditioned beauty), are ascribed to objects that stand under the concept of a particular end." 46 Invoking this distinction can lead to a possible method for avoiding the mistakes I have outlined thus far.

Each type of beauty suggests a type of judgment. Free judgments of taste are reflective judgments because they involve the free play of the imagination and the understanding in a way that does not employ concepts. Adherent judgments of beauty, on the other hand, can be thought of as involving the judgment of something as being beautiful of a kind. In fact, most art that we see (and which is beautiful) is of the adherent variety. ${ }^{47}$ To conceptualize the adherence relation, Paul Guyer writes (referring to a view he once held) that "In the case of adherent beauty, the concept of the object that is presupposed by the judgment constrains or restricts what forms we can find

${ }^{46}$ Kant, op cit.

${ }^{47}$ Some have noted the possibility that free beauty isn't a relevant category when discussing fine art. As Hannah Ginsborg notes, "The distinction is important because Kant suggests that all judgments of beauty about representational art are judgments of adherent rather than of free beauty, and hence that they are all impure. While some art works can be 'free beauties,' the examples Kant gives are all of non-representational art: 'designs a la grecque, foliage for borders or on wallpaper...fantasias in music', and indeed, Kant adds, all music without a text (\$16). It might be supposed from this that Kant's core account of judgments of beauty is only peripherally applicable to art, which would make it largely irrelevant to the concerns of contemporary aesthetics." Ginsborg, op cit. 
beautiful in an object of a certain sort by considerations deriving from its intended function, but such constraints are not sufficient to determine what forms we will find beautiful in such an object." 48 When we see a work of art we see it as a member of a particular class or genre. That is, when we view a painting, it is a portrait, or a cubist painting, or a historical allegory; it is never just a painting. The category in which the painting is placed is a constraint on our aesthetic judgment making our aesthetic judgments adherent judgments. We condition our judgment on the extent to which the object fulfills its purpose as a member of the genre to which it belongs.

This conception of adherent beauty is related to Kendall Walton's discussion in "Categories of Art," where he argues that aesthetic properties (and thus, aesthetic judgments) are contingent upon the category within which the judged artwork belongs. He further proposes that the placement of artworks within categories is based on nonaesthetic features (what he terms standard, variable, and contrastandard features) and can be done (at least in many circumstances) correctly or incorrectly. ${ }^{49}$ If the categories alter our aesthetic judgments then, as Sheila Lintott notes, what "we know and learn about a work's nonaesthetic features does affect our aesthetic appreciation of an object, first by helping us classify an object and then by defining a range of reasonable expectations regarding the object." 50 Our aesthetic expectations of a work are shaped by its nonaesthetic features. The concepts adhering in adherent beauty provide a constraint on our judgment of beauty. If this is the case, the nonaesthetic might help us to get a handle on the issue of aesthetic judgments, which do not admit of proofs.

Walton's "categories" can be seen as the presupposed concepts of adherent beauty. Using this strategy, the art critic could outline the ways the categories adhere to instances of adherent beauty. The adherence relation employs concepts, and thus can admit proofs, making it less subjective than aesthetic judgments. Further, there are objective points that one can make concerning this adherence relation making its specification a possible role for the critic. For example, if you were to put Monet's Waterlilies in a photorealist show you would be forced to say that Monet's painting either (1) is not any good or (2) does not belong in the show. Since, most of us are committed to the opposite of (1) it is safe to say that (2) is the more plausible explanation. That is, if you were to believe that the concept of photorealism adhered to Monet's $W$ aterlilies you would have done something wrong and a critic could tell you so.

How can this help us to avoid the types of mistakes outlined in this paper? It has already been noted that since beauty is not a property, it cannot

48 Guyer, Values of Beanty: Historical Essays in Aesthetics.

${ }^{49}$ In Walton's words, "[ $[\mathrm{t}$ seems that, at least in certain cases, it is correct to perceive a work in certain categories, and incorrect to perceive it in certain others; that is, out judgments of it when we perceive it in the former are likely to be true, and those we make when perceiving it in the latter false." K. Walton, "Categories of Art," in Philosophical Review, 79 (1970), 339-367.

${ }^{50}$ S. Lintott, "Adjudicating the Debate Over Two Models of Nature Appreciation," in Journal of Aesthetic Education, 38:3 (2004), 52-72. 


\section{MAKING JUDGMENTS}

be the category into which works will fall. Similarly, the agreeable cannot be such a category. However, certain categories normally elicit (or should elicit) judgments of taste or judgments of the agreeable. We have already seen how this could be said of the categories Kant lists as being exemplars of agreeable art, which include "entertaining narrative, the art of starting the whole table in unrestrained and sprightly conversation, or with jest and laughter inducing a certain air of gaiety," among others. These aesthetic categories should (in most cases) elicit a judgment of the agreeable. Similarly, what are often called the fine or beaux arts (opera, ballet, painting, poetry, sculpture, architecture, and classical music) should elicit a judgment of taste from viewers. The fact that we think that the fine arts should elicit judgments of taste is one reason why the potential classification of an art-form as a fine art (related to food, for example) is such a contentious and messy business. ${ }^{51}$ And, of course, there are many borderline cases between those categories that should elicit a judgment of taste as those that should elicit a judgment of beauty (such as food, video games, and television). It is here that a critic, classifying artworks into Walton's categories, could aid viewers in ascertaining the appropriate type of judgment. In most circumstances, if we can correctly categorize a work we will be able to know whether a "perfect" (or good, etc.) work in that category should elicit a judgment of taste or a judgment of the agreeable.

Consider again the example of Monet's $W$ aterlilies. You could say to your acquaintance who did not like the $W$ aterlilies any one of the following things (all of which would be in accordance with the strategy I am currently outlining): (1) "I think you're looking at the painting as a bad example of a photorealism, when it is actually a good example of impressionism. And impressionist paintings, when they're as fine as Monet's, are supposed to elicit the judgment that they are beautiful." (2) "Painting is one of the beaux arts and as such it is meant to elicit your judgment that the work is beautiful and that everyone should think that it is beautiful." Or finally, (3) "The category of museum quality paintings (of which the Waterlilies is one since it is hung in one of the world's foremost museums) is supposed to engage our cognition and thus elicit a judgment that the work is beautiful, not merely agreeable."

These methods can only amount to arguments concerning the categories to which the works belong and not arguments concerning the aesthetic judgments elicited by works in question (since these judgments do not employ concepts). In addition, in aesthetics sense perception and cognition are not analytically distinct. As a result, we will still make mistakes, but using my proposed strategy we will potentially have an easier time noting both (1) when we make mistakes and (2) when others make mistakes. We will then be able to argue on the basis of categorization, a task which employs concepts and thus proofs, what category a work should belong to and thus, whether a judgment

51 Stanley Cavell suggests that that "the familiar lack of conclusiveness in aesthetic judgment, rather than showing up an irrationality, shows the kind of rationality it has." S. Cavell, "Aesthetic Problems of Modern Philosophy," in Must We Mean What We Say? (New York: Scribner, 1969). 
concerning the work probably should elicit a judgment of taste or a judgment of the agreeable.

In aesthetics, the satisfaction of the senses and the satisfaction of the cognition cannot be successfully analytically distinguished. As a result, we will on occasion mistake judgments of the agreeable for judgments of taste and vice versa. Using categories as aids to our judgment, however, could help minimize these errors. Arguments concerning the categories to which the works belong are easier to resolve as they are conditional on concepts. Critics can engage in these debates, helping to define categories that viewers can use to help them (1) know when they are making mistakes, and (2) know when others are making mistakes. We will then be able to argue on the basis of categorization, a task which employs concepts and thus proofs, whether a judgment concerning the work should most likely elicit a judgment of taste or a judgment of the agreeable. However, categorization will not completely eliminate these mistakes from our aesthetic lives. Therefore, these mistakes still threaten the framework of a Kantian aesthetics.

\section{Conclusion}

This paper has provided some initial arguments for why judgments of taste and judgments of the agreeable might not be analytically distinguishable. Further work will be required to definitively determine if this is indeed the case. But if this is so, it threatens the Kantian aesthetic project. That is, if sense and taste are not distinguishable then it is unclear when the demand that we share in each others judgments of taste is justified. This, in turn, threatens the entire foundation of aesthetics. For if there is no realm in which judgments of taste are appropriate (and nothing we can turn to determine conclusively that they are appropriate) then defining (and upholding) a realm of aesthetics becomes increasingly difficult. Kant writes of this possibility in \$57: "If, by contrast, agreeableness were to be assumed as the determining ground of taste (on account of the singularity of the representation that is the basis of the judgment of taste), as it is be some, or the principle of perfection were to be assumed, as it is by others, and the judgment of taste were to be fixed accordingly, then from that there would arise an antinomy that could not be resolved at all except by showing that both of the opposed propositions are false: which would then prove that the concept on which each is based is selfcontradictory." 52 In the first clause Kant is outlining the mistake of taking judgments of taste for judgments of the agreeable and in the second clause he is doing the reverse. He concludes that if either of these were to hold, the antinomy of taste could not be resolved and thus, aesthetics would not be left on very firm ground. This, unfortunately, is the situation that we are left in given the mistakes that we make regarding judgments of the beautiful and judgments of the agreeable. As these mistakes seem to likely be based in an

\footnotetext{
${ }^{52}$ Kant, op cit.
} 


\section{MAKING JUDGMENTS}

inability of people to differentiate sense from taste, the mistakes are unlikely to be resolved.

The tendency of humans to try to demand universality of judgments of the agreeable could be reinforced by our interactions with others. We usually talk about art with others who are like us, or share our preferences. Perhaps we surround ourselves with people who share our preferences because we want others to have the same aesthetics judgments as we do. This might lead us, however, to make demands of universality in judgments of agreeable where such universality cannot be demanded. This might signify that aesthetic subcultures are connected (and separated from other aesthetic subcultures) through judgments of the agreeable and also that we believe and want judgments of taste to connect us with the rest of humanity. This is an area worthy of further research.

Department of Philosophy, Temple University, United States

\section{References}

Allison, H. E., Kant's Theory of Taste, A Reading of the Critique of Aesthetic Judgment (Cambridge: Cambridge University Press, 2001).

Burnham, D., An Introduction to Kant's Critique of Judgment (Edinburgh: Edinburgh University Press, 2000).

Cavell, S., "Aesthetic Problems of Modern Philosophy," in Must We Mean What We Say? (New York: Scribner, 1969).

Gilbert, D., Stumbling on Happiness (New York: Knopf, 2006).

Ginsborg, H., "Kant's Aesthetics and Teleology," in The Stanford Encyclopedia of Philosophy (2005).

Gracyk, T., Hume and Kant: Summary and Comparison (2004).

Guyer, P., Kant and the Claims of Taste (Cambridge: Cambridge University Press, 1997).

Guyer, P., V alues of Beanty: Historical Essays in Aesthetics (Cambridge: Cambridge University Press, 2005).

Hume, D., "Of the Standard of Taste," in Essays: Moral, Political, and Literary, trans. by E. F. Miller (Indianapolis: Liberty Fund, 1985).

Kant, I., Critique of the Power of Judgment (Cambridge: Cambridge University Press, 2000).

Lintott, S., "Adjudicating the Debate Over Two Models of Nature Appreciation," in Journal of Aesthetic Education, 38:3 (2004), 52-72.

Walton, K., "Categories of Art," in Philosophical Review, 79 (1970), 339-367.

Zangwill, N., "Kant on Pleasure in the Agreeable," in Journal of Aesthetics and Art Criticism, 53:2 (1995), 167-176.

Zangwill, N., "Aesthetic Judgment," in The Stanford Encyclopedia of Philosophy (2003). 